Brit. Heart f., 1967, 29, 725.

\title{
Operative Treatment of Atrial Septal Defect: Clinical and Hæmodynamic Assessments in 175 Patients
}

\author{
LAWRENCE H. COHN, ANDREW G. MORROW, AND EUGENE BRAUNWALD
}

From the Clinic of Surgery and the Cardiology Branch, National Heart Institute, Bethesda, Maryland, U.S.A.

Atrial septal defect is one of the most common congenital cardiovascular malformations, and as a result cardiologists have become generally familiar with its various clinical and hæmodynamic manifestations, and surgeons with the methods of operative treatment required. Relatively less information is available, however, concerning the effectiveness of operation as measured by the results of detailed pre- and post-operative evaluations. The present report describes such evaluations, carried out in $\mathbf{1 7 5}$ patients with atrial septal defect, who were studied and operated upon at the National Heart Institute.

\section{Selection of Patients}

The 175 patients described were studied and operated upon consecutively between February 1958 and July 1965. Atrial septal defects of the septum secundum type were proved to be present in 150 patients, and sinus venosus defects, associated with partial anomalous pulmonary venous connexion, in the remaining 25 . Patients with the incomplete form of persistent $A-V$ canal, and those in whom atrial septal defect was associated with another congenital or acquired cardiovascular malformation that required concomitant treatment were excluded from the analysis.

\section{Clinical Descriptions}

Age and Sex. The 175 patients, of whom 70 were male and 105 female, ranged in age from 4 to 65 years; 41 were less than 13 years, and 37 were more than 40 years. The sex distribution was identical among patients with secundum and sinus venosus defects.

Symptoms and Historical Data. One-hundred and fifty patients were symptomatic before operation. Exertional dyspncea and decreased exercise tolerance were the most frequent symptoms, and were described by 97 patients. Thirty-one patients had had frequent respiratory infections, 28 palpitations, 10 retarded growth, 17

Received January 2, 1967. substernal chest pain, 13 recurrent tachycardia, and 4 had experienced syncope. Twenty-nine patients were under treatment for heart failure or much reduced cardiac reserve at the time of initial evaluation. Only 25 patients were completely asymptomatic, as judged by both prospective and retrospective analysis, and they were initially referred solely because a heart murmur or cardiomegaly had been detected on a routine examination.

\section{Physical Findings}

Right ventricular enlargement, indicated by a palpable right ventricular lift, was evident in 144 of the 175 patients. A systolic thrill along the left sternal border was palpable in 16 patients, only 7 of whom subsequently proved to have a systolic pressure gradient between the right ventricle and pulmonary artery greater than $10 \mathrm{~mm}$. Hg. Fixed splitting of the second heart sound throughout the respiratory cycle was present in 161 patients; $14(8 \%)$ exhibited normal splitting of the second sound during respiration, a finding verified in each instance by phonocardiography. The pulmonary component of the second sound was increased in intensity in 133 patients. An early systolic ejection sound was audible at the pulmonary area in 24 of the 175 patients $(13 \%)$, but was not consistently related to increased pulmonary arterial pressure, as only 4 patients with this finding had a systolic pulmonary arterial pressure greater than $50 \mathrm{~mm}$. Hg. A systolic ejection murmur, best heard in the second and third left intercostal spaces, was detected in 173 of the 175 patients; the usual intensity was grade $2 / 6$ or $3 / 6$. In one patient only a diastolic murmur characteristic of pulmonary regurgitation was present, and in another only a tricuspid flow murmur was audible. Murmurs characteristic of pulmonary regurgitation were noted in 14 patients, and only 7 of these had systolic pulmonary artery pressures greater than 30 725 
$\mathrm{mm}$. Hg. A rumbling diastolic murmur, maximal at the left lower sternal border, and increasing with inspiration, was audible in 31 patients. Of these 31 patients, 20 had a pulmonary to systemic flow ratio $(\mathrm{Qp} / \mathrm{Qs})$ greater than 2:0/1·0. Cyanosis was present in 4 patients, left ventricular heaves in 9, and sustained systemic hypertension in 4 .

\section{ELECTROCARDIOGRAPHIC FINDINGS}

Sinus rhythm was present in 163, nodal rhythm in one, and atrial fibrillation in 5 patients. The remaining 6 patients had coronary sinus rhythm, and 5 of them had sinus venosus defects. An RSR' complex in right præcordial leads was evident in 111 of the 175 patients, and complete right bundle-branch block was present in 23 of them. Electrocardiographic evidence of right ventricular hypertrophy without an 'RSR' complex in right præcordial leads was found in 12 patients.

Ninety-nine patients presented with either right or vertical axis. Ten patients exhibited left axis deviation which, though unusual in secundum type atrial septal defect, is a finding that has been previously documented (Harrison and Morrow, 1963). Right atrial enlargement was indicated in 31 patients. In 6 other patients the $P$ wave in lead II was broad and notched. Although this configuration is generally considered to represent left atrial enlargement, it has previously been observed in patients with atrial septal defect and probably results from a disturbance of intra-atrial conduction (Sánchez-Cascos and Deuchar, 1963). The electrocardiograms of 4 patients were entirely normal.

\section{Radiological Findings}

The right ventricle and main pulmonary artery were enlarged in 130 of the 175 patients. Increased prominence of the pulmonary vasculature was evident in 155 patients, and ranged in severity from a mild increase to frank plethora. A radiological diagnosis of pulmonary hypertension, indicated by increased central vascularity and tapering of pulmonary arteries toward the periphery, was made in 14 patients, all of whom were subsequently shown to have systolic pulmonary arterial pressures greater than $70 \mathrm{~mm}$. Hg. The radiographic appearance of the heart and great vessels was normal in only 3 of the 175 patients.

\section{HAMODYNAMIC FINDINGS}

All patients were studied before operation by right heart catheterization. The presence, site, and magnitude of the left-to-right shunt was established by the results of inhaled ${ }^{85} \mathrm{Kr}$ (Sanders and Morrow, 1959) or $\mathrm{N}_{2} \mathrm{O}$ tests (Morrow, Sanders, and
Braunwald, 1958), and also by oximetry when a bidirectional shunt was present. Arterial indicatordilution curves were also recorded in all patients after injections into the right side of the heart, and usually after injections into the left atrium, left ventricle, and one or more pulmonary veins.

The right ventricular systolic pressure was 30 $\mathrm{mm}$. $\mathrm{Hg}$ or more in 101 of the 175 patients, and 30 had a right ventricular systolic pressure of 50 $\mathrm{mm}$. Hg or more. In most of these patients the pulmonary arterial systolic pressure was equal to that in the right ventricle, but in several younger patients significant flow gradients between the right ventricle and pulmonary artery were recorded. Increase of the right ventricular end-diastolic pressure above the normal level of $6 \mathrm{~mm}$. $\mathrm{Hg}$ was noted before operation in 35 patients. The right ventricular end-diastolic pressure was $10 \mathrm{~mm}$. Hg or more in 10 patients, 9 of whom had raised right ventricular systolic pressures.

The left ventricle was catheterized, via the interatrial communication, in 126 patients, and in 5 the left ventricular end-diastolic pressure was abnormally high ( $>12 \mathrm{~mm}$. Hg). Four of these patients had $\mathrm{Qp} / \mathrm{Q}$ s greater than $2 \cdot 0 / 1 \cdot 0$, and the fifth had a systolic pulmonary arterial pressure of $95 \mathrm{~mm}$. Hg. All but one of the 5 patients with abnormal left ventricular end-diastolic pressures also had abnormally raised right atrial mean pressures.

Systolic pressure gradients between the right ventricle and pulmonary artery were recorded in 112 patients, ranging from 1 to $33 \mathrm{~mm} . \mathrm{Hg}$, and averaging $6 \mathrm{~mm}$. Hg. In atrial septal defect, such pressure gradients have been attributed to increased blood flow across a relatively rigid valve ring which does not dilate to the same extent as the pulmonary artery (Schrire and Vogelpoel, 1964). Among the present patients, however, there was no correlation between the magnitude of the "flow" gradient and the magnitude of the pulmonary to systemic flow ratio. Of the 112 patients with gradients, only 19 had a Qp/Qs in excess of $2 \cdot 5 / 1.0 ; 11$ had a Qp/Qs greater than $3 \cdot 0 / 1 \cdot 0$. Of 19 patients with gradients of $10 \mathrm{~mm} . \mathrm{Hg}$ or more, only $10 \mathrm{had}$ a $\mathrm{Qp} / \mathrm{Qs}$ in excess of $2 \cdot 0 / 1 \cdot 0$. Fifty-eight patients demonstrated pressure gradients in excess of $5 \mathrm{~mm} . \mathrm{Hg}$, and again no correlation with the $\mathrm{Qp} / \mathrm{Qs}$ could be discerned.

The mean pressure was recorded as the cardiac catheter was withdrawn from the left atrium to the right, across the interatrial defect, in 159 patients; in 82 a small pressure differential from 1 to 5 $\mathrm{mm} . \mathrm{Hg}$ (average 1.8) was noted; the left atrial always exceeded the right atrial pressure. The average size of the defects in these 82 patients, as determined at operation, was approximately $3 \mathrm{~cm}$. This finding contrasts with a popular conception 
that with defects greater than $2 \mathrm{~cm}$. the two atria are functionally a common chamber and that the pressures in them are identical (Nadas, 1963).

In every patient a left-to-right shunt was shown to enter the right atrium. The $Q p / Q$ s ranged from $1 \cdot 2 / 1 \cdot 0$ to $6 \cdot 0 / 1 \cdot 0$, and averaged $2 \cdot 1 / 1 \cdot 0$. Right-toleft shunts at the atrial level were demonstrated in 40 patients by arterial indicator-dilution curves recorded after injections into the venæ cavæ or right atrium.

Attempts were made to define the drainage pathways of the pulmonary veins in all patients, by comparison of the appearance times and contours of arterial indicator-dilution curves recorded after injections into the pulmonary veins, right atrium, and venæ cavæ (Braunwald, Lombardo, and Morrow, 1960). In 25 patients such pre-operative assessments indicated partial anomalous pulmonary venous connexions, and in 19 of these patients sinus venosus defects and anomalous right pulmonary venous connexions were found at operation; in the other 6 , large defects of the secundum type were present. In the other 6 patients who proved to have sinus venosus defects, the correct diagnosis was not established before operation, usually because indicator-dilution curves from appropriate sites of injection could not be obtained. Indicator-dilution curves were recorded after left atrial injections in $\mathbf{1 7}$ patients with sinus venosus defects; in 10 of the 17 patients no left-to-right shunt was apparent, indicating that in them the shunt originated almost entirely from the anomalous pulmonary veins.

\section{OpERATIVE METHODS}

All patients were operated upon with the use of cardiopulmonary bypass. The early and generally unsatisfactory experience in this clinic with the operative treatment of atrial septal defect during inflow occlusion and general hypothermia has previously been reported (Morrow et al., 1960). A complete median sternotomy was almost universally employed, though right thoracotomies were used in some patients. The heart-lung machine consisted of a disc oxygenator and roller pumps, and in most instances was primed with heparinized whole blood which had been drawn from donors 48 hours previously. Bypass was conducted at $37^{\circ} \mathrm{C}$, and flow rates of $2 \cdot 0-2 \cdot 21 . / \mathrm{min} . / \mathrm{m}^{2}$ were provided.

The septum secundum defects were of the recognized anatomical types, i.e. foramen ovale, inferior vena cava, and posterior; they ranged in diameter from 1 to $6 \mathrm{~cm}$. In some instances two defects separated by strands of fibrous tissue were present, and were converted to a single defect by excision of the intervening tissue. In 129 patients with septum secundum defects the interatrial septum was re- constituted with a patch of knitted teflon fabric, and the specific operative methods are illustrated in Fig. 1 and 2. Only 21 secundum defects were closed by direct suture. The sinus venosus defects were all repaired by the insertion of a teflon fabric patch which partitioned the superior vena cava and right atrium in such a manner as to direct the flow from the upper and middle lobe pulmonary veins into the left atrium (Fig. 3-5).

Interatrial communications were closed with perforated prostheses in 6 adult patients, 5 of whom had severe pulmonary hypertension and bidirectional shunts. The sixth patient had systemic hypertension and had had pulmonary œdema and left ventricular failure; in him the perforated patch was employed to permit decompression of the left rather than the right ventricle in the early postoperative period. Four of these patients had secundum defects, and 2 had sinus venosus defects. All of these 6 patients survived operation.

\section{RESULTS OF OPERATION}

Six of the 175 patients $(3.4 \%)$ died at or following operation. All 6 patients had septum secundum defects, and the principal causes of death in each patient are summarized in Table I. Post-operative complications of greater or lesser significance occurred in 88 of the 175 patients, and these are summarized in Table II. Arrhythmias represented more than half of all complications, and atrial flutter, atrial fibrillation, and rapid nodal rhythm were most frequently observed. In only 3 patients did a postoperative arrhythmia (atrial fibrillation) persist until discharge. The methods in this clinic for the management of post-operative arrhythmias, and the other frequent complications of cardiac operations, have been presented elsewhere in detail (Williams, Morrow, and Braunwald, 1965).

\section{Post-operative Clinical and Hamodynamic CORrelations}

Of the 169 patients who survived operation, 154 returned to the Institute for detailed clinical and hæmodynamic assessments at an average interval of 7 months after operation. For various reasons cardiac catheterization was not carried out after operation in the remaining 15 patients and, though their clinical examinations indicate a satisfactory operative result, they have been excluded from further analysis.

Complete abolition of the circulatory shunt, and a right ventricular systolic pressure less than 40 $\mathrm{mm} . \mathrm{Hg}$ were demonstrated after operation in 133 patients. The absence of a shunt was proved in all 


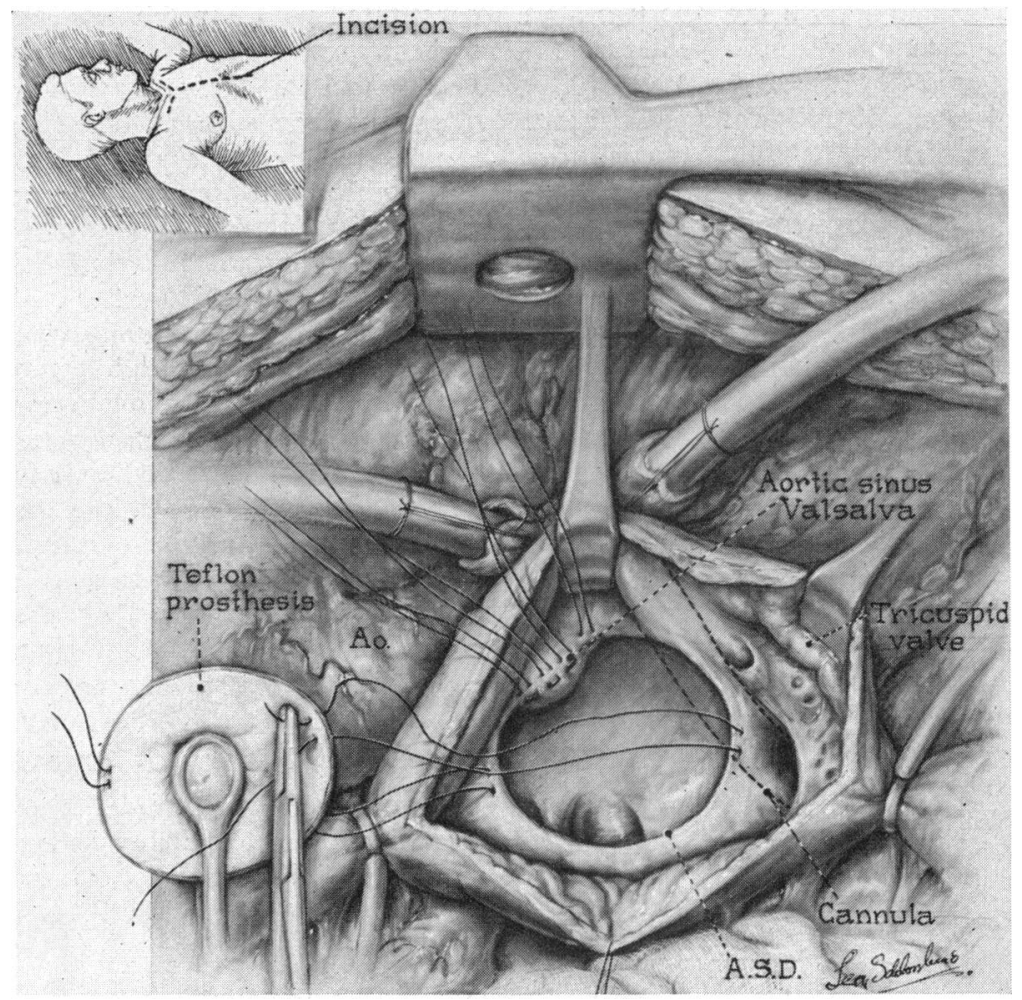

FIg. 1.-Operative exposure and methods in the repair of a large atrial septal defect of the septum secundum (foramen ovale) type. After caval cannulation and the institution of cardiopulmonary bypass a right atriotomy is made. The margins of the defect are defined, and mattress sutures placed at the upper and lower poles. A series of interrupted sutures is placed when the intracardiac portion of the aortic root comprises a margin of the defect, or when no septal remnant remains posteriorly or inferiorly. The sutures are placed through the margin of a teflon prosthesis cut to appropriate shape.

patients by the results of the inhaled foreign gas tests, and by the appearance times and contours of indicator-dilution curves recorded after injections in the right heart and/or pulmonary artery. Of these 133 patients without significant residual hæmodynamic abnormalities, 125 were asymptomatic; all of the remaining 8 patients described symptomatic improvement, but some limitation of

TABLE I

PRINCIPAL AND CONTRIBUTORY CAUSES OF DEATH IN 6 PATIENTS WHO DIED AFTER OPERATIONS FOR ATRIAL SEPTAL DEFECT

\begin{tabular}{|c|c|c|c|c|c|}
\hline Patient, & age, & and sex & $\begin{array}{l}\text { Prior treatment } \\
\text { for congestive } \\
\text { failure }\end{array}$ & $\begin{array}{l}\text { Pulmonary } \\
\text { artery pressure } \\
(\mathrm{mm} . \mathrm{Hg})\end{array}$ & Circumstances of death \\
\hline 1 & 8 & $\mathbf{F}$ & Yes & $47 / 34$ & \multirow{6}{*}{$\begin{array}{l}\text { Tracheobronchitis, severe respiratory insufficiency, hypoxia leading } \\
\text { to cardiac arrest; no tracheostomy } \\
\text { Tracheobronchitis, respiratory insufficiency, tracheostomy; acute } \\
\text { upper gastro-intestinal bleeding, perforated gastric ulcer, death } \\
\text { during laparotomy } \\
\text { Obliterative pleuritis, right lung lacerated when drainage tube } \\
\text { placed; massive bleeding post-operatively necessitating lobec- } \\
\text { tomy; death during second operation } \\
\text { Staphylococcal infection of mediastinum and pericardium; prophy- } \\
\text { lactic antibiotics not given during this period (1960) } \\
\text { Inferior cava partially directed to left atrium at previous operation; } \\
\text { death from air embolism at second operation } \\
\text { Acute myocardial infarction on day of hospital discharge; necropsy } \\
\text { performed }\end{array}$} \\
\hline 2 & 5 & $\mathbf{M}$ & No & $30 / 8$ & \\
\hline 3 & 65 & $\mathbf{F}$ & Yes & $\begin{array}{l}33 / 5 \\
\text { (R.V.) }\end{array}$ & \\
\hline 4 & 51 & $\mathbf{F}$ & Yes & $95 / 30$ & \\
\hline 5 & 43 & $\mathbf{F}$ & No & $33 / 12$ & \\
\hline 6 & 59 & $\mathbf{F}$ & Yes & $68 / 36$ & \\
\hline
\end{tabular}




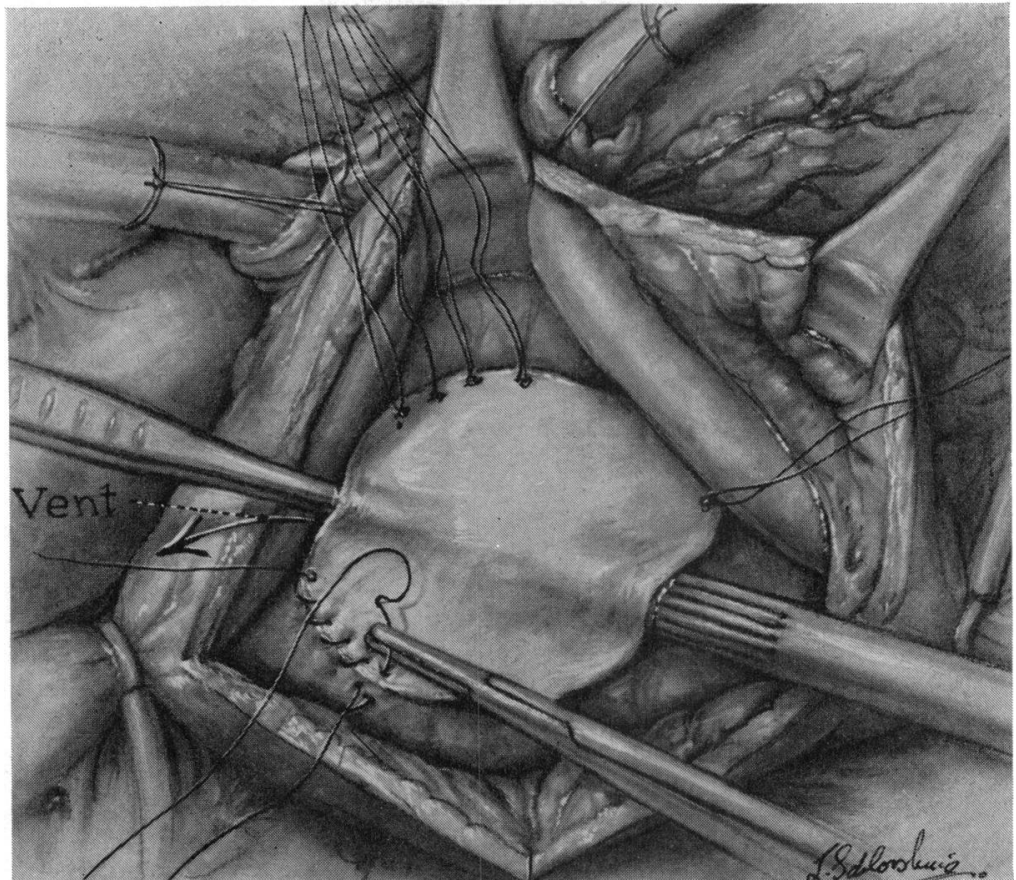

Fig. 2.-The prosthesis is drawn into place, and the interrupted sutures tied. The repair is completed with continuous sutures which approximate the prosthesis to the septum. The anterior-superior margin is closed last, and as these sutures are drawn tight air is carefully evacuated from the left atrium.

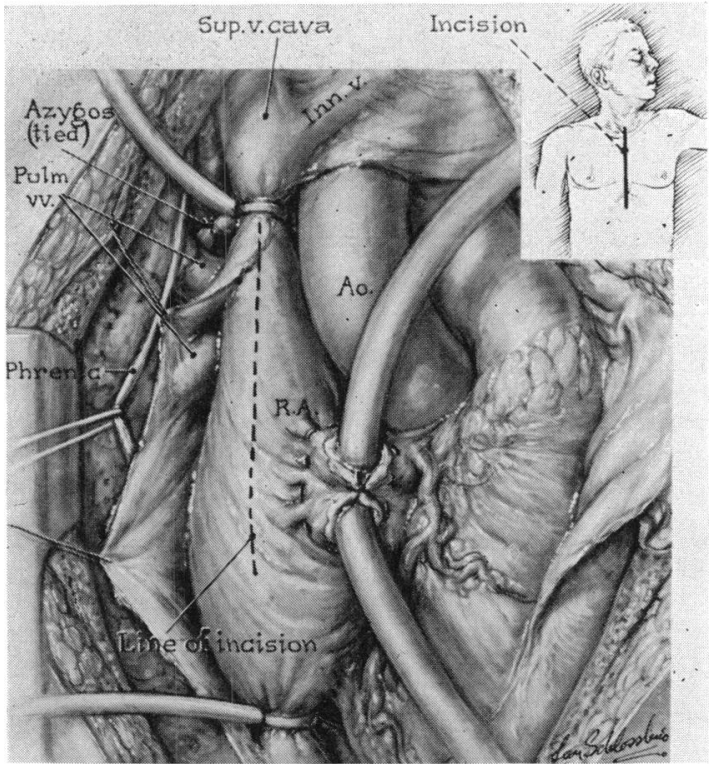

FIG. 3.-Operative exposure in the repair of a sinus venosus type of atrial septal defect with associated anomalous pulmonary venous connexion to the superior vena cava and right atrium. The occluding tape around the superior vena cava must be placed well above the entrance of the highest pulmonary vein, and ligation of the azygos vein is often necessary. A vertical incision in the right atrium is extended into the superior vena cava as shown.
TABLE II

SIGNIFICANT NON-FATAL POST-OPERATIVE COMPLICATIONS AMONG 175 PATIENTS OPERATED UPON FOR ATRIAL SEPTAL DEFECT

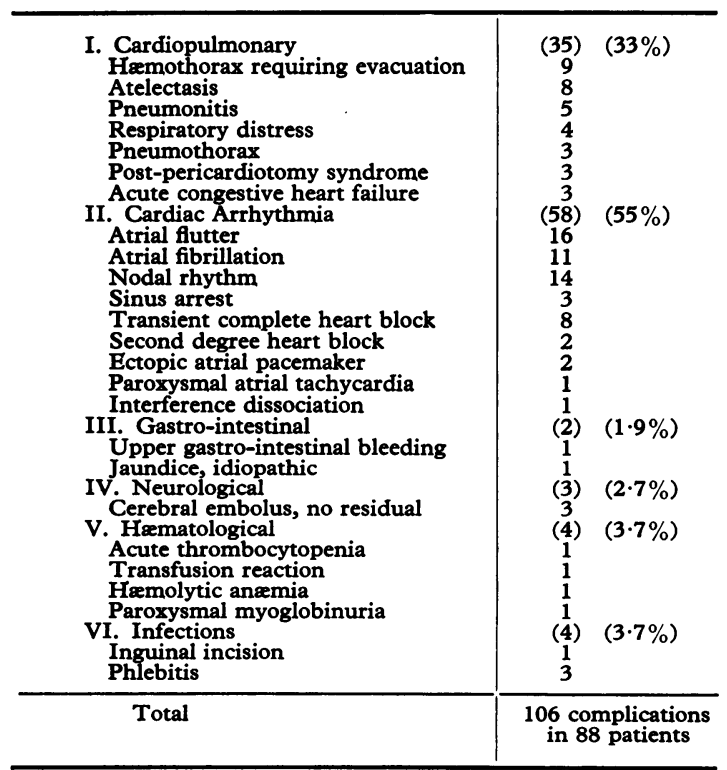




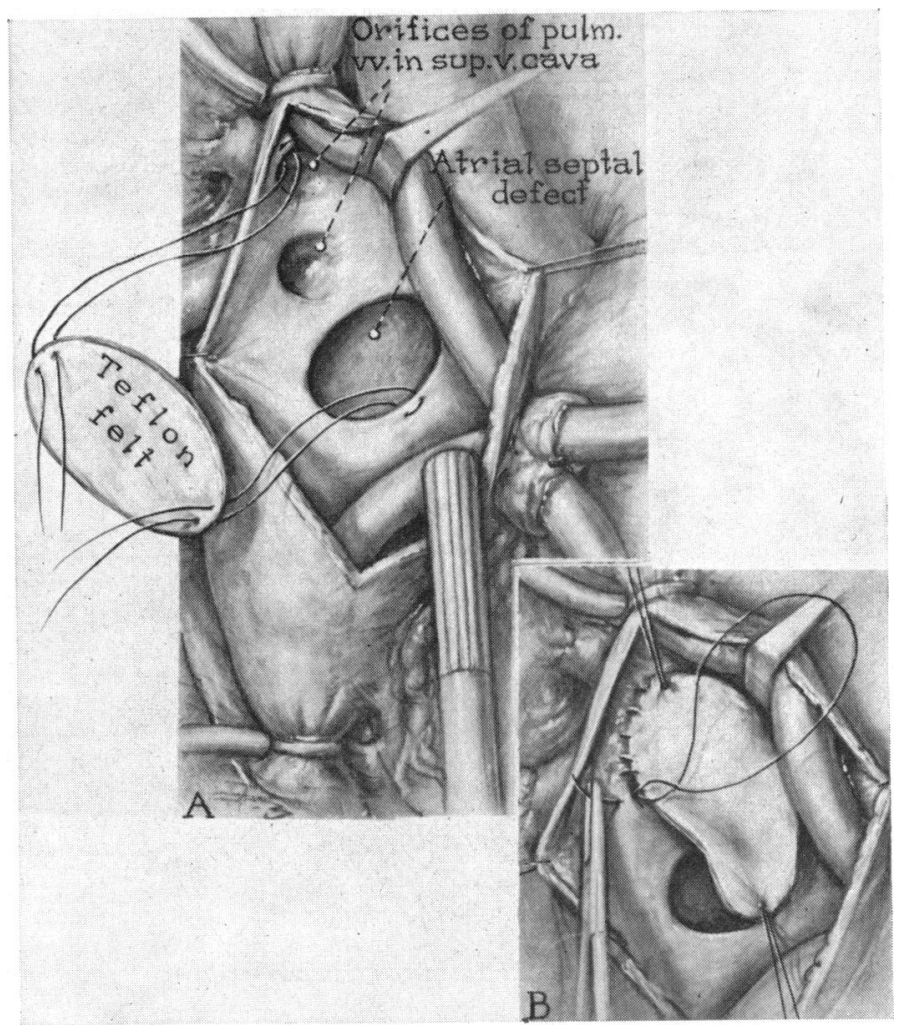

FIG. 4.-The high-lying interatrial defect and the orifices of the pulmonary veins are exposed by retraction of the cannula, and a patch of teflon is cut to such a size and shape as to cover both, and partition the cava and right atrium. The prosthesis is anchored with interrupted sutures and the repair completed with continuous sutures.

exercise activity or mild dyspnœea on exertion persisted (Functional Class II). Sixteen of the 133 patients had been in congestive heart failure before operation; of this number, 13 were asymptomatic and 3 were improved.

The second heart sound varied normally with respiration in 125 patients, but in 8 persistent fixed splitting of the second heart sound was present. A systolic murmur was no longer audible in 76 patients. Electrocardiographic evidences of some degree of right ventricular hypertrophy were still present in 76 patients, 18 of whom had had severe pulmonary hypertension $(24 \%)$. The changes in rate of growth which occurred after operation were determined in the 36 children (less than 12 years of age) in this group, and many evidenced a spurt in growth. Within 6 to 12 months the weight of 30 of the 36 patients increased from an average percentile of 25 to one of 51. Nineteen patients increased their height percentiles, from an average of 40 to an average of 63 .
Systolic pressure gradients between the right ventricle and pulmonary artery in excess of 5 $\mathrm{mm}$. $\mathrm{Hg}$ disappeared after operation in 23 of the 53 patients in this group in whom such gradients had been demonstrated before operation. In those in whom gradients persisted, they ranged from 1 to $10 \mathrm{~mm} . \mathrm{Hg}$, and averaged $4 \mathrm{~mm}$. Hg. Normal right ventricular end-diastolic pressures were demonstrated in 28 of the 31 patients in whom this pressure was abnormally raised before operation.

Twenty-three patients who had severe pulmonary hypertension before operation (right ventricular systolic pressure $50 \mathrm{~mm}$. Hg or greater) were studied after surgery. In 14 the systolic right ventricular pressure was less than $40 \mathrm{~mm}$. $\mathrm{Hg}$, and in 7 it was $30 \mathrm{~mm} . \mathrm{Hg}$ or less (Fig. 6). Of these 14 patients, also considered in the foregoing analysis, 2 (ages 44 and 56) had been in congestive heart failure. One of them was asymptomatic after operation.

In the 9 remaining patients the right ventricular 


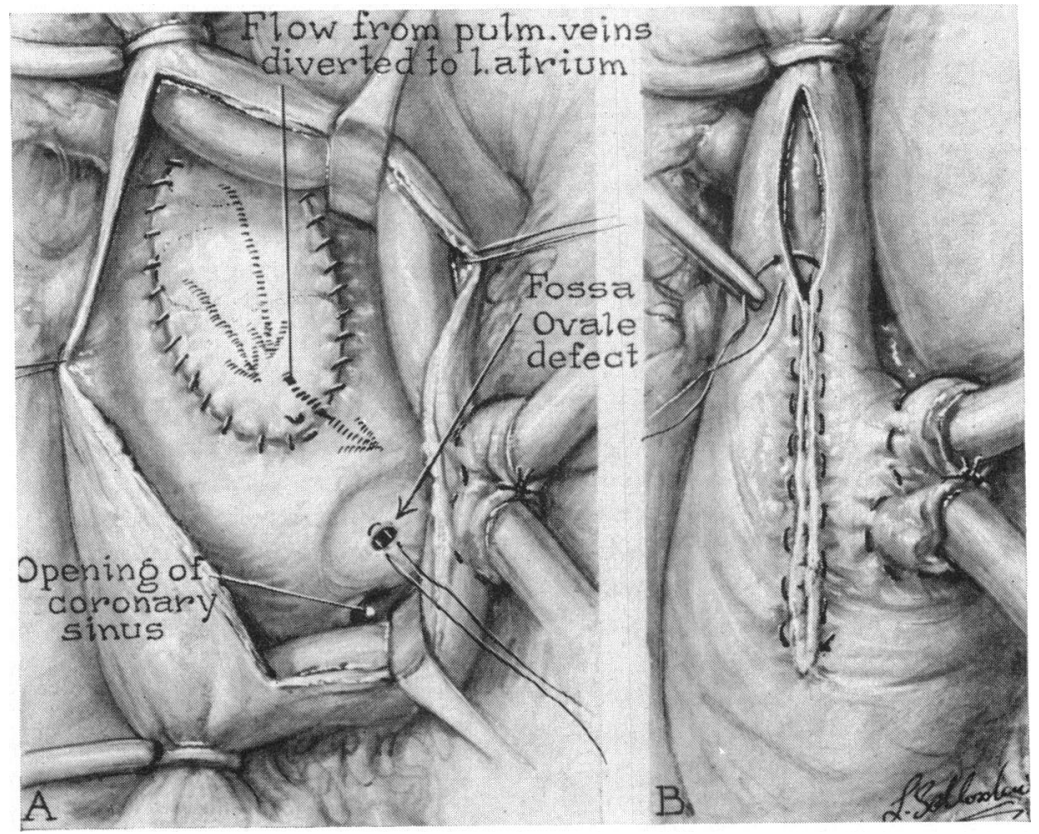

Fig. 5.-Final appearance of the repair. The blood returned from the pulmonary veins is diverted beneath the prosthesis, through the defect, and into the left atrium. The incision in the atrium and cava is closed with an everting suture to assure approximation of the intima, and care is taken that the caval lumen is not narrowed. In this patient the foramen ovale was patent and was closed by a single suture.

systolic pressure was reduced in comparison to the pre-operative level, but was still $40 \mathrm{~mm}$. $\mathrm{Hg}$ or more. These 9 patients ranged in age from 12 to 44 years at operation, and 4 of them had been in congestive heart failure. After operation, 8 of the patients with residual right ventricular hypertension were asymptomatic, and one was improved. All had electrocardiographic evidence of right ventricular hypertrophy before operation, and this finding persists in 8 . The right ventricular enddiastolic pressure was raised before operation in 3 of these 9 patients, and after operation in 2. Three patients had systolic pressure gradients between the right ventricle and pulmonary artery before operation, and in each no gradient was evident at postoperative study.

The interatrial defect was closed with a perforated prosthesis in 5 of the 30 patients who had severe pulmonary hypertension before operation, and have been included in that analysis. The detailed hæmodynamic findings in 4 of these patients have been presented previously (Braunwald and Morrow, 1963), and the pre- and post-operative right ventricular pressures in all 5 are included in Fig. 6 . The right ventricular pressure in one patient fell from 100 to $35 \mathrm{~mm}$. $\mathrm{Hg}$, but in the others the systolic pressure remains at or near pre-operative levels. In 4 patients determinations of the pulmonary to systemic resistance ratio were made both before and after operation. All were raised before $(0.29$ to 0.55 , average 0.44 ), and no significant changes occurred after operation, the ratios ranging from 0.36 to 9.55 . One patient has no residual shunt through the prosthesis ( 36 months); 2 have negative ${ }^{85} \mathrm{Kr}$ inhalation tests, but small left-to-right shunts are evident on indicator-dilution curves (8 and 12 months); the remaining 2 patients have residual left-to-right shunts resulting in $Q p / Q s$ of 1.1 and $1 \cdot 2: 1$, respectively. No patient has a right-to-left shunt.

Residual left-to-right shunts were found at postoperative cardiac catheterization in 11 of the 148 patients in whom immediate and complete correction of the malformation had been attempted, i.e. patients in whom a perforated prosthesis was not inserted. Eight of the patients had secundum defects, and 3 had venosus defects. In 4 patients with residual shunts secundum defects had been closed by direct suture, a method no longer employed in this clinic. Seven of the 11 patients were asymptomatic after operation, and 6 of them had small shunts, Qp/Qs being $1.3 / 1.0$ or less. The 3 patients who improved (Class II) have larger shunts $(Q p / Q s 1 \cdot 3-1 \cdot 5 / 1 \cdot 0)$, but a further operation was not recommended. The remaining patient 


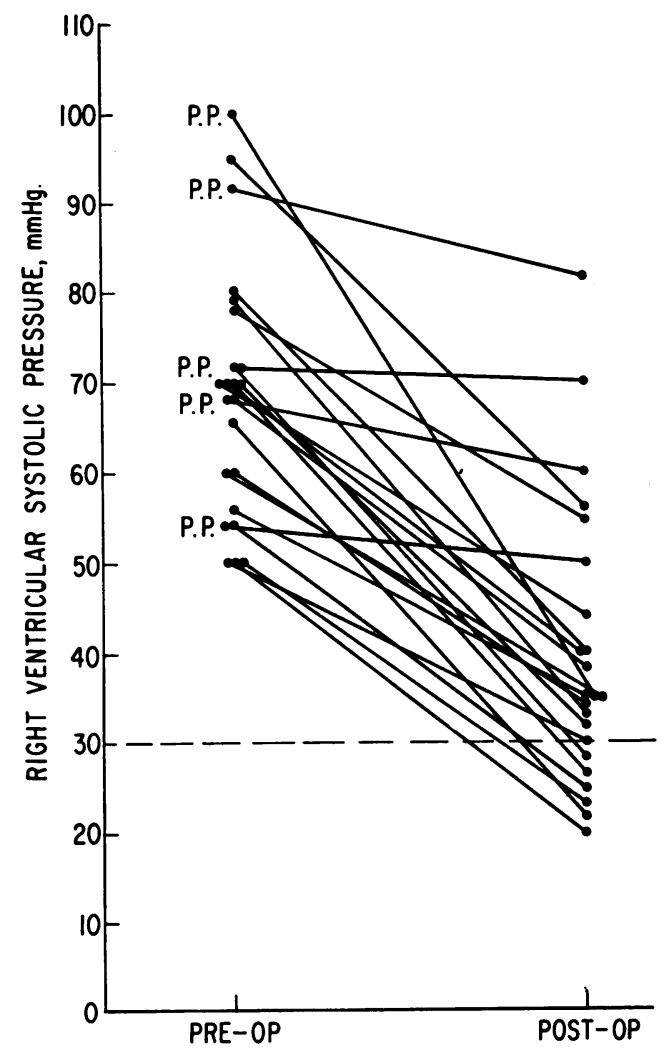

FIG. 6.-Graphic representation of the right ventricular systolic pressures recorded before and after operation in 23 patients with atrial septal defect, and in whom the pre-operative pressure was $50 \mathrm{~mm}$. $\mathrm{Hg}$ or greater. Points designated P.P. indicate those patients in whom the defect was closed with a perforated prosthesis.

is the only one in the entire group of operative survivors whose symptoms became worse after operation. Before operation, he had only slight exertional dyspnoea, and $Q p / Q s$ was $2 \cdot 0 / 1 \cdot 0$. Three months after operation he became distinctly more symptomatic, and developed left and right heart failure; only a small residual shunt was demonstrated at catheterization, but the right atrial and right ventricular end-diastolic pressures were strikingly raised. $\mathrm{He}$ was considered to have developed a cardiomyopathy of unknown type. In 9 of the 11 patients who later proved to have residual shunts, appropriate arterial indicator-dilution curves were recorded at the conclusion of the operative procedure (Morrow et al., 1966). In 3 patients the contours of the curves were normal, indicating that a complete repair was achieved, but was followed by recurrence of the defect; in 6 patients the intraoperative curves were abnormal, indicating that the initial repair was incomplete.
One additional patient, not previously described, was found to have a small $(\mathrm{Qp} / \mathrm{Q} s=1 \cdot 2 / 1 \cdot 0)$ residual shunt after repair of a secundum defect. Postoperative hæmodynamic and angiographic studies demonstrated that the defect was closed, and that the shunt resulted from a previously unrecognized connexion of a left pulmonary vein to a left vena cava. He was asymptomatic.

\section{COMMENT}

In this clinic a decision concerning the advisability of operative treatment in a patient with atrial septal defect is arrived at only after both clinical and hæmodynamic assessments. Operation has usually been recommended to any patient, symptomatic or not, when a pulmonary to systemic flow ratio $1.5 / 1.0$ or greater is demonstrated at cardiac catheterization. Infants, unless in severe cardiac decompensation, or patients with serious intercurrent disease constitute infrequent exceptions to this general policy. When severe pulmonary hypertension and a bidirectional shunt are demonstrated at pre-operative study, operation has been advised whenever the net flow through the defect has been shown to be left to right; in such patients gradual closure of the communication with a perforated prosthesis has generally been employed. The results of operative treatment in the 175 patients described indicate that these criteria are generally valid ones in the management of patients with atrial septal defect.

Six of the 175 patients $(3.4 \%)$ died at or following operation, and the principal contributory factors are worthy of comment. Four of the patients were adults, all over 40 years of age; 3 of them had been treated for congestive heart failure, and 2 had severe pulmonary hypertension. These factors, prior congestive heart failure, advanced age, and pulmonary hypertension, have been designated in other reports as contributing to an increased operative risk in atrial septal defect (McGoon et al., 1959; Gross, 1962; Sellers et al., 1966). In 3 of these patients, however, these factors were not directly responsible for the deaths which resulted from technical errors (air embolism, lung laceration, infection). The deaths of the two children were probably the result of the inadequate methods utilized in managing post-operative respiratory complications at the time they were operated upon (1958). With the exception of the patient who died of myocardial infarction, it is likely that none of the patients would have died if present methods of operative and post-operative management had been available, a conjecture attested by the fact that no patient has died following operation for atrial septal defect within the past four years. 
The post-operative hæmodynamic studies revealed that complete abolition of the circulatory shunt was achieved in 137 of 148 patients (93\%) in whom immediate complete closure of the defect was attempted, an incidence of complete repair similar to that reported by Sellers and associates (Sellers et al., 1966). Fortunately, the residual shunts have generally been small, and no patient has required a second operation. Incomplete repairs may be largely obviated by more precise operative methods. Direct suture of secundum defects is inadvisable, since dehiscence of the suture line may result when the heart fills with blood (Morrow et al., 1960); among the 21 patients in whom secundum defects were sutured, residual shunts were demonstrated in $4(19 \%)$. When a prosthesis is utilized in either a secundum or sinus venosus defect, it must be accurately and securely fixed, preferably with synthetic non-absorbable sutures. With a sinus venosus defect, it is also necessary that all the right pulmonary veins be identified before the prosthesis is placed, since a residual shunt may result from an unrecognized segmental pulmonary vein entering the vena cava at or even above the level of the azygos vein. Finally, the adequacy of the repair may be immediately assessed by appropriate intraoperative indicator-dilution curves, and if a residual shunt is demonstrated a further attempt at correction may be indicated (Morrow et al., 1966).

Severe pulmonary hypertension did not prove to be a significant direct cause of increased mortality and morbidity in the group of patients described. Twelve patients had right ventricular systolic pressures of $70 \mathrm{~mm}$. Hg or greater; one died, of a mediastinal infection. Among surviving patients who had right ventricular hypertension before operation, however, 16 of 23 still had an abnormally raised pressure $(>30 \mathrm{~mm} . \mathrm{Hg}$ ) after operation. In a similar group of 11 patients reported by Beck and associates (Beck et al., 1960), the pulmonary arterial systolic pressure remained greater than $40 \mathrm{~mm}$. $\mathrm{Hg}$ in 6 patients after operation; in patients with normal pressures at rest, increases to abnormal levels were observed with muscular exercise. Unlike patients with large ventricular septal defects, where pulmonary vascular changes may begin in infancy (Shepherd, 1959), pulmonary vascular disease is rarely seen before the third decade of life in patients with atrial septal defect (Dexter, 1956), a finding substantiated by this study. It has been postulated that the hæmodynamic sequelæ of an atrial septal defect, high pulmonary flow at a low pulmonary arterial pressure, require 20 or more years to produce pulmonary vascular disease. Thus, despite complete repair of the defect, varying degrees of increased pulmonary vascular resistance persist in many older patients following operation. The important question as to whether the pulmonary vascular resistance may ultimately fall can be answered only by the results of hæmodynamic studies performed at much later post-operative intervals.

\section{SUMMARY}

The results of operative treatment were assessed in 175 patients with atrial septal defects; 150 had defects of the septum secundum type, and 25 had sinus venosus defects with partial anomalous pulmonary venous connexion. Forty-one patients were younger than 13 years, 37 older than $40 ; 150$ patients were symptomatic, and 29 were under treatment for heart failure. Cardiac catheterization was performed in every patient before operation, and left-to-right shunts resulting in pulmonary to systemic flow ratios of $1 \cdot 2 / 1 \cdot 0$ to $6 \cdot 0 / 1.0$ were demonstrated. Right-to-left shunts were present in $\mathbf{4 0}$ patients. The right ventricular systolic pressure was abnormally high ( $>30 \mathrm{~mm}$. $\mathrm{Hg}$ ) in 101 patients, and it was $50 \mathrm{~mm} . \mathrm{Hg}$ or greater in 30 .

During cardiopulmonary bypass, 129 secundum defects were closed with prostheses, 21 by direct suture; prostheses which partitioned the atrium and cava and diverted the return from the anomalous pulmonary veins were utilized in all sinus venosus defects. Perforated intracardiac prostheses were employed in 5 patients with extreme pulmonary hypertension and bidirectional shunts; all survived. Six of the 175 patients $(3.4 \%)$ died at or following operation, and significant but not fatal complications occurred in 88 patients.

Detailed post-operative clinical and hæmodynamic evaluations were performed in 154 surviving patients; 135 are asymptomatic, 18 improved, and one patient worse as the result of cardiomyopathy. Complete abolition of circulatory shunts was proved at post-operative cardiac catheterization in 93 per cent $(137 / 148)$ of patients in whom complete closure was attempted. In no patient has a residual shunt necessitated further operation. Of 30 patients with right ventricular systolic pressure greater than $50 \mathrm{~mm}$. $\mathrm{Hg}$ before operation, 23 were recatheterized; 7 have normal pressures, while in 16 the right ventricular pressure was found to be reduced but still abnormal.

\section{REFERENCES}

Beck, W., Swan, H. J. C., Burchell, H. B., and Kirklin, J. W. (1960). Pulmonary vascular resistance after repair of atrial septal defects in patients with pulmonary hypertension. Circulation, 22, 938.

Braunwald, E., Lombardo, C. R., and Morrow, A. G. (1960). Drainage pathways of pulmonary veins in atrial septal defect. Brit. Heart f., 22, 385. 
Braunwald, N. S., and Morrow, A. G. (1963). The delayed closure of atrial septal defects with perforated prostheses. Surg. Gynec. Obstet., 116, 579.

Dexter, L. (1956). Atrial septal defect. Brit. Heart f., 18, 209.

Gross, R. E. (1962). Atrial septal defects of the secundum type. Progr. cardiovasc. Dis., 4, 301.

Harrison, D. C., and Morrow, A. G. (1963). Electrocardiographic evidence of left-axis deviation in patients with defects of the atrial septum of the secundum type. New Engl. F. Med., 269, 743.

McGoon, D. C., Swan, H. J. C., Brandenberg, R. O. Connolly, D. C., and Kirklin, J. W. (1959). Atrial septal defect: factors affecting the surgical mortality rate. Circulation, 19, 195.

Morrow, A. G., Gilbert, J. W., Baker, R. R., and Collins, N. P. (1960). The closure of atrial septal defects utilizing general hypothermia. F. thorac. cardiovasc. Surg., 40, 776.

-, Oldham, H. N., Callard, G. M., and Braunwald, E. (1966). The assessment of operative results in congenital heart disease by intraoperative indicator-dilution curves. Circulation, 33, 263.

- Sanders, R. J., and Braunwald, E. (1958). The nitrous oxide test. An improved method for the detection of left-to-right shunts. Circulation, 17, 284.
Nadas, A. S. (1963). Pediatric Cardiology, 2nd ed., p. 366. Saunders, Philadelphia.

Sánchez-Cascos, A., and Deuchar, D. (1963). The P wave in atrial septal defect. Brit. Heart f., 25, 202.

Sanders, R. J., and Morrow, A. G. (1959). The identification and quantification of left-to-right circulatory shunts : a new diagnostic method utilizing the inhalation of a radioactive gas, $\mathrm{Kr}^{85}$. Amer. F. Med., 26, 508 .

Schrire, V., and Vogelpoel, L. (1964). Atrial septal defect. Amer. Heart f., 68, 263.

Sellers, R. D., Ferlic, R. M., Sterns, L. P., and Lillehei, C. W. (1966). Secundum type atrial septal defects: early and late results of surgical repair using extracorporeal circulation in 275 patients. Surgery, 59, 155.

Shepherd, J. T. (1959). The pulmonary circulation in the presence of interatrial, interventricular and interarterial communications. In Pulmonary CirculationAn International Symposium, 1958, ed. W. R. Adams and I. Veith, pp. 204-215. Grune and Stratton, New York.

Williams, J. F., Jr., Morrow, A. G., and Braunwald, E. (1965). The incidence and management of "medical" complications following cardiac operations. Circulation, 32, 608. 